\title{
Do walk-in centres for commuters work? A mixed methods evaluation
}

\author{
Alicia O'Cathain, Joanne Coster, Chris Salisbury, \\ Tim Pearson, Ravi Maheswaran and Jon Nicholl
}

\begin{abstract}
\section{Background}

Between 2005 and 2007, six pilot walk-in centres were opened in or near train stations, to provide health care to commuters. They are run by independent providers on behalf of the NHS, providing access to doctors and nurses.
\end{abstract}

Aim

To evaluate the policy of commuter walk-in centres.

Design of study

Mixed methods evaluation.

Setting

Six centres in England.

\section{Method}

Site visits, interviews with 28 users, survey of 1828 users, economic estimates, and interviews with six commissioning managers.

Results

Each centre was located near a train station, although two were not within the main commuter flow. The average number of patients attending each centre on days when the user survey was undertaken was between 33 and 101 per day, considerably lower than the planned capacity of 150-180. Sixty-two per cent $(1004 / 1627)$ of users identified themselves as commuters within the user survey, and 38\% (95\% confidence interval $=13 \%$ to $62 \%$ ) had travelled to work by train that day. A large proportion of users worked in the local area (61\%). The estimated cost per attendance, based on limited activity and price data, was between $£ 52$ and $£ 150$ for different centres at estimated current activity levels. Primary care trust managers' plans for the future of the centres involved changing the focus of the service to fit their local health economy.

\section{Conclusion}

Pilot walk-in centres placed near train stations for commuters had low activity levels and high costs. A policy of placing healthcare centres in areas of high worker density may be more successful.

Keywords

access to health care; evaluation studies; primary health care.

\section{INTRODUCTION}

In 2000, the NHS introduced 40 walk-in centres in England, with the aim of improving accessibility to health care through provision of nurse-led advice about minor illness and injury. ${ }^{1}$ A national evaluation concluded that this new service offered some benefits to patients, providing safe and high-quality care. ${ }^{2}$ However, these benefits were at an additional cost and there were concerns about competing claims for NHS resources from patients with higher health needs. In 2004, an expansion of walk-in centres occurred, with new centres co-located with emergency departments to relieve pressure on services and offer an appropriate level of care in the place people chose to attend. This initiative was evaluated as unsuccessful because hospitals did not implement the concept as planned and it therefore had little effect on processes or outcomes. ${ }^{3}$ It was also the case that many patients preferred to access care in traditional settings. ${ }^{4}$

In 2004 the government announced a further set of walk-in centres, to be located in or near to national

A O'Cathain, BSc, MSc, MA, $P h D$, senior research fellow; $J$ Coster, BA, MSc, research associate, School of Health and Related Research, University of Sheffield, Sheffield.

C Salisbury, MD, MSc, FRCGP, professor of primary health care; Academic Unit of Primary Health Care, University of Bristol, Bristol. T Pearson, BSc, NMedSci, research associate; R Maheswaran, MD, MRCP, MFPHM, clinical senior lecturer; J Nicholl, BA, MSc, DSc, FFPH, director of Medical Care Research Unit, School of Health and Related Research, University of Sheffield, Sheffield.

Address for correspondence

Alicia O'Cathain, Medical Care Research Unit, School of Health and Related Research, University of Sheffield, Sheffield S1 4DA. E-mail: a.ocathain@sheffield.ac.uk

Submitted: 12 March 2009; Editor's response: 7 May 2009; final acceptance: 15 July 2009.

() British Journal of General Practice

This is the full-length article of an abridged version published in print. Cite this article as: Br J Gen Pract 2009; DOI: 10.3399/bjgp09X473150. 
rail stations in England aimed in particular at commuters. ${ }^{5}$ As part of a $£ 50$ million change to primary care services, seven pilot commuter walk-in centres were funded for a period of 5 years. Between 2005 and 2007 six of the pilot centres were opened, three in London and three in large cities in the north of England. They differ from the existing set of walkin centres in three ways. First, they are managed by the private sector, offering care on behalf of the NHS. Second, they provide access to doctors, whereas general walk-in centres are mainly nurse led. Third, they have opening hours to suit commuters: 7 am to $7 \mathrm{pm}$ Monday to Friday compared with general walkin centres open from $7 \mathrm{am}$ to $10 \mathrm{pm}$ every day. Although targeted at commuters, the centres are also available to the general population. Their planned capacity was 180 patients per day for centres based in London and 150 per day for those based outside London. The centres are commissioned directly by the Department of Health, with the intention that local commissioning organisations - primary care trusts (PCTs) - would host them in the future. This study evaluated this pilot initiative, after agreeing a number of objectives with the Department of Health, including exploring the location and organisation of the centres; activity levels; user characteristics, expectations, and satisfaction; the cost per attendance; and local commissioners' views.

\section{METHOD}

\section{Study design}

The definition of 'commute' is to travel daily or regularly to and from one's place of work in a city by any means of conveyance (Oxford English Dictionary). Given the policy drive to locate the walkin centres near train stations, the definition of commuter for this evaluation was someone who 'travels regularly by train to and from one's work'. The design was a mixed methods evaluation using a combination of quantitative and qualitative methods concurrently. Methods consisted of site visits to each centre, interviews and a survey of users (see accompanying paper), ${ }^{6}$ a simple economic costing, and interviews with managers from the PCTs hosting the centres. An analysis of routine activity data from each centre was planned.

\section{Site visits}

Each centre was visited to assess location and facilities offered. Assessments included distance from the train station, the flow of commuter traffic to and from the train station, and visibility of signage, tested by walking around the outside of the train station and walking between the train station and the centre during the evening rush hour. Pedestrian traffic was assessed by standing outside each centre

\section{How this fits in}

Walk-in centres have been provided in England for the general population since 2000. This study evaluated a pilot scheme to offer walk-in centre care to a subgroup of the population - people commuting to work by train. It was found that these centres operated more as 'worker walk-in centres' than 'commuter walk-in centres'. The location of centres was key to the numbers and types of users, which provides an important message for those commissioning new primary care services such as GP-led centres.

for three 15-minute time periods and counting the numbers of pedestrians walking past. The location of areas of high density of workers was assessed by discussions with centre staff, observation of the area, and use of local maps. The researchers met with the centre manager or other staff members to discuss the service aims, facilities, staffing, triage and patient management, information management, and activity. A structured proforma was completed for each centre.

\section{Activity data}

The protocol for the study, which was funded by the Department of Health, included an analysis of anonymised routine data from each centre to consider the activity. However, the Department of Health subsequently decided that these data were confidential and that they could not be freely reported on. Instead, data from the user survey (described below) were used to undertake a crosssectional analysis of activity levels and patient characteristics.

\section{User interviews and survey}

Face-to-face semi-structured interviews were undertaken with 28 users to understand why people used the centres and the aspects of the service important to patients. All users attending on days specified by the research team were surveyed. Each centre was asked to record attendance on these 'questionnaire days' for use by the research team. There were an estimated 5574 users on the questionnaire days and 1828 (33\%) completed questionnaires. User experience and satisfaction is reported in an accompanying paper. ${ }^{6}$ Responders gave their residential postcodes on the questionnaire and the straight line distance between the user's residential postcode centroid and the centre postcode location was calculated to determine the distance between a user's home and the service.

\section{Economic costing}

Since centres are provided by non-NHS organisations, the true costs of providing the service were unobtainable due to the commercial sensitivity 
Table 1. Location of commuter walk-in centres.

\begin{tabular}{|c|c|c|c|c|c|c|}
\hline \multirow[b]{2}{*}{ Site } & \multicolumn{3}{|c|}{ In London } & \multicolumn{3}{|c|}{ Out of London } \\
\hline & A & $\mathrm{B}$ & $\mathrm{C}$ & D & $E$ & $\mathrm{~F}$ \\
\hline Distance from train station, miles & $<0.5$ & $<0.5$ & $<0.5$ & $<0.5$ & $<0.5$ & $<0.5$ \\
\hline On the main commuter flow & No & Yes & Yes & No & Yes & Yes \\
\hline $\begin{array}{l}\text { Number of pedestrians passing } \\
\text { centre in three } 15 \text {-minute periods }\end{array}$ & $s^{190}$ & 1115 & 554 & 161 & 1215 & 1559 \\
\hline Visible signage in train station & No & Yes & No & No & No & No \\
\hline Near or in area of worker density & Yes & Yes & Yes & No & Yes & Yes \\
\hline
\end{tabular}

of this information. The 'price per attendance' was estimated based on the probable price paid for the service over the 5-year contract, obtained from press releases, ${ }^{5}$ and activity data obtained from the user survey questionnaire days. The contract price is the sum paid for the service by the NHS, and in this context is therefore equal to the cost of the service to the NHS. The study also considered how this would change if attendances operated at the planned daily activity level, and at current activity levels.

In addition, the cost of the service if the NHS were to provide it was estimated by identifying details about the key driver of costs, that is, staffing. The number of whole-time equivalent staff and their approximate grades were obtained from the centre managers during the site visits. Clinical staff were costed, including overheads, on-costs (employer costs), and capital overheads (building-related costs, for example, rent/lease costs) from NHS pay scales and the relevant unit costs of health and social care. ${ }^{7}$ Non-clinical staff were costed using the midpoint of any salary range..$^{8}$ Because no on-cost or overhead information was available for non-clinical staff, the ratio of salary to on-costs/overheads for clinical staff was taken and applied to the non-clinical staff, in order to estimate the non-clinical staff costs including employer costs and overheads.

Interviews with local commissioners

Local commissioners were interviewed to explore how each centre fitted into the local health economy. The Department of Health identified a local commissioner from the PCT hosting each centre. This commissioner was contacted to gain informed consent for an interview. Semi-structured telephone interviews were undertaken with the six commissioners, lasting on average 17 minutes (range 11-26 minutes). Interviews were recorded and transcribed verbatim. Framework analysis was used to identify the key issues facing local commissioners of this service. ${ }^{9}$ The interviewees worked in the urgent care directorates of their PCTs, and most of them had been in their current post for a short time only.

\section{RESULTS}

\section{Location}

All centres were located within 0.5 miles of a train station and none within a train station. One was situated on the main access road to the train station, one in a hotel/office complex, two in shopping centre/arcades, and two on side streets just off main roads. Two centres ('A' and 'D') were not situated on the main commuter flow and had low-density pedestrian traffic compared with the other centres during the study observation periods (Table 1). For five of the centres there were no visible signs to the service in the train stations. Some centre managers informed us that they had requested signs but these were not allowed by the train station authorities or were subject to lengthy negotiation procedures. All centres were assessed as situated within or extremely close to high-density worker areas, with the exception of centre ' $D$ '. All of the PCT managers felt that the location of the centre was extremely important and two felt that their centre was in an excellent location for commuters. However, PCT managers had concerns about the other four centres in terms of whether they were located in the best position for commuters and workers, whether they were visible and easily found, and whether there was sufficient footfall in the area:

Table 2. Reported daily activity of centres at site visits and on user survey 'questionnaire days'.

\begin{tabular}{lcccccccc} 
& \multicolumn{3}{c}{ In London } & & \multicolumn{3}{c}{ Out of London } \\
\cline { 2 - 4 } & $\mathrm{A}$ & $\mathrm{B}$ & $\mathrm{C}$ & & $\mathrm{D}$ & $\mathrm{E}$ & $\mathrm{F}$ \\
\hline Reported average daily use (from site visit) & 88 & 100 & 102 & & 47 & 100 & 95 \\
Range & - & $63-121$ & $90-128$ & & $30-80$ & $30-120$ & $80-120$ \\
\hline Number of questionnaire days & 14 & 12 & 10 & & 12 & 12 & 13 \\
\hline Number of days activity data provided & 12 & 6 & 4 & & 3 & 7 & 1 \\
\hline Mean daily use on questionnaire days & 78 & 93 & 101 & & 33 & 94 & 64 \\
Range & $63-103$ & $76-107$ & $93-110$ & & $24-49$ & $79-122$ & $64-64$ \\
\hline Number of months open at October 2007 & 19 & 23 & 11 & & 18 & 9 & 24 \\
\hline
\end{tabular}


Table 3. Description of facility and staffing of the centres, based on site visit.

\begin{tabular}{|c|c|c|c|c|c|c|}
\hline \multirow[b]{2}{*}{ Site } & \multicolumn{3}{|c|}{ In London } & \multicolumn{3}{|c|}{ Out of London } \\
\hline & A & $\mathrm{B}$ & C & $\mathrm{D}$ & $\mathrm{E}$ & $\mathrm{F}$ \\
\hline Approximate size of facility $\left(\mathrm{m}^{2}\right)$ & 315 & 232 & Not known & 530 & 209 & 353 \\
\hline Number of consultation rooms & 5 & 5 & 7 & 7 & 6 & 5 \\
\hline Number of WTE nurses & 6 & 8 & 6 & 5.8 & 6 & 5.5 \\
\hline Number of WTE doctors & 1.6 & 1.5 & 2 & 2 & 1.7 & 1.5 \\
\hline Number of WTE other clinical staff & 0 & 0 & 0 & 0 & 0.3 & 0 \\
\hline Number of receptionist/admin staff & 4.1 & 4 & 1 & 2.3 & 4.5 & 3.5 \\
\hline Number of non-clinical managerial staff & 1 & 0 & 1 & 1 & 0 & 2 \\
\hline Number of clinical managerial staff & 1 & 1 & 1 & 0 & 1 & 1 \\
\hline Nurse triage in operation & No & No & Yes & Yes & No & No \\
\hline
\end{tabular}

WTE $=$ whole-time equivalent.

\section{Online Table 4. Characteristics of users, based on user survey.}

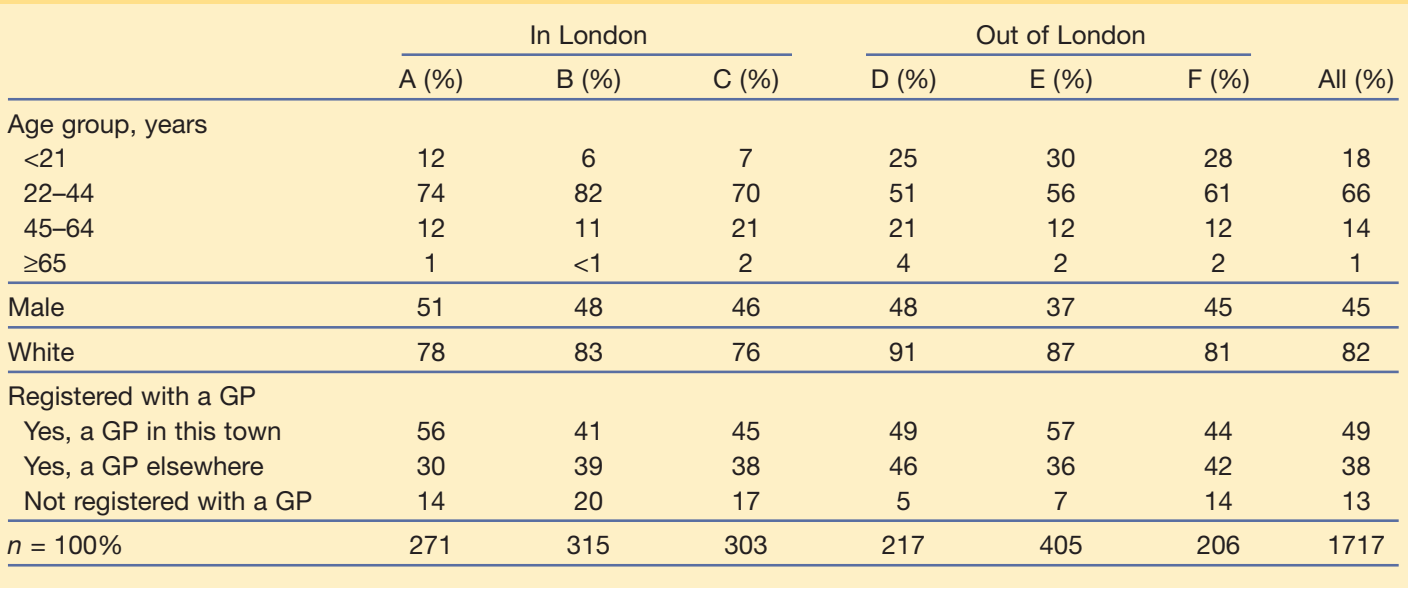

'I think if you're trying to get commuters, it's the best one [location] you could have.'

'The principle of location is crucial, and I think where it is currently located could be better. It could be more centrally located, nearer to the station, and more centrally within the hub of offices.'

\section{Utilisation}

During the site visits, undertaken between July and September 2007, centre managers reported an average estimated daily attendance of 87 (Table 2). The maximum reported daily use was 128 for any centre. On the days on which the user survey was undertaken, between September and November 2007, the average daily attendance varied between 33 and 101. Three of the PCT managers felt that there were problems with these centres seeing less than the desired numbers of patients per day and that location was central to this:

'I don't know whether you'd get a different cohort of people but I think you'd get more people if it was situated differently.'

\section{Facilities and services offered}

At the time of the site visits, centres were staffed by an average of 1.7 whole-time equivalent (WTE) doctors and six WTE nurses, with variation between sites (Table 3). Centres ' $C$ ' and ' $D$ ' operated a nurse triage system. During site visits, centre managers were asked to describe the main health problems seen and these were: minor illness/injury; treatment of minor cuts/wounds; bites and stings; emergency contraception; health advice/promotion; coughs and colds; strains and sprains; minor skin complaints; minor eye infections; advice on local services.

\section{Characteristics of users}

Based on the user survey, the majority of users were under 45 years old and very few were over 65 years (Table 4). The age distribution varied by centre $(P<0.001)$, with those out of London attracting a higher proportion of under $21 \mathrm{~s}$ than those in London. The managers of these centres reported 
Table 5. Percentage of users commuting and working near the centres.

\begin{tabular}{|c|c|c|c|c|c|c|c|}
\hline & \multicolumn{3}{|c|}{ In London } & \multicolumn{3}{|c|}{ Out of London } & \multirow[b]{2}{*}{ All (\%) } \\
\hline & $A(\%)$ & $\mathrm{B}(\%)$ & C (\%) & $\mathrm{D}(\%)$ & $\mathrm{E}(\%)$ & $F(\%)$ & \\
\hline Commuter & 67 & 78 & 69 & 49 & 55 & 45 & 62 \\
\hline Travelled by train that day & 52 & 61 & 56 & 14 & 13 & 18 & 38 \\
\hline \multicolumn{8}{|l|}{ Proximity to work } \\
\hline Near & 66 & 73 & 60 & 53 & 59 & 50 & 61 \\
\hline Pass it & 12 & 17 & 21 & 11 & 14 & 20 & 16 \\
\hline N/A & 22 & 10 & 19 & 36 & 26 & 29 & 23 \\
\hline$n=100 \%$ & 258 & 293 & 312 & 201 & 368 & 195 & 1627 \\
\hline \multicolumn{8}{|l|}{ Distance travelled (miles) ${ }^{\mathrm{a}}$} \\
\hline$\leq 0.99$ & 33 & 11 & 10 & 12 & 14 & 30 & 17 \\
\hline $1-4.99$ & 30 & 33 & 38 & 51 & 53 & 41 & 42 \\
\hline $5-9.99$ & 19 & 26 & 22 & 19 & 14 & 14 & 19 \\
\hline 10-19.99 & 9 & 12 & 15 & 6 & 8 & 5 & 9 \\
\hline $20-39.99$ & 4 & 11 & 7 & 4 & 5 & 4 & 6 \\
\hline$\geq 40$ & 6 & 7 & 8 & 9 & 6 & 6 & 7 \\
\hline$n=100 \%$ & 235 & 278 & 231 & 195 & 366 & 186 & 1491 \\
\hline
\end{tabular}

${ }^{a}$ Of the 1828 people who completed a questionnaire, 1491 provided a residential postcode that could be georeferenced using the National Statistics Postcode Directory.

that they actively marketed to students. Most users were white, with a higher proportion of users from minority ethnic groups in the London centres than outside London centres $(P<0.001)$. Thirteen per cent of users reported that they were not registered with a GP and this varied by centre $(P<0.001)$, being more prevalent for centres within rather than out of London.

Centre managers were asked for their definition of a commuter. One manager was not keen on identifying their service as a 'commuter walk-in centre' because they wanted to promote the service more generally to people who lived locally. About two-thirds of users identified themselves as commuters, although this varied in and out of London, and the proportion was nearer a half for centres outside London (Table 5); 38\% (95\% confidence interval $[\mathrm{Cl}]=13 \%$ to $62 \%$ ) of users commuted by train that day, and again the differences in and out of London were stark, with a half of users in London travelling to work by train compared with only one-sixth of users of centres outside London (57\% versus 16\%). One-fifth of users lived over 10 miles away from the centre they attended. The distance between home and the commuter walk-in centre differed by centre $(P<0.001)$, with two services ' $A$ ' and ' $F$ ' drawing on a very local population of a 1-mile radius. There was an expectation that commuters would use centres on their way to and from work, making location of sites near train stations essential. Only $16 \%$ of users reported passing the centre on their way to work, but $61 \%$ reported that they worked nearby.

\section{Economics}

A 5-year contract price for the centres was estimated, based on available media press releases of a $£ 50$ million investment in primary cares services outside hospitals. If the 5-year contract price per centre is estimated at $£ 8000000$ for London-based services and £6 400000 for non-London-based services, and they reach their planned capacity of

Table 6. Estimated price $(£)$ per attendance and cost per attendance.

\begin{tabular}{|c|c|c|c|c|c|c|}
\hline & \multicolumn{3}{|c|}{ In London } & \multicolumn{3}{|c|}{ Out of London } \\
\hline & A & B & C & D & $\mathrm{E}$ & $\mathrm{F}$ \\
\hline Total contract price & 8000000 & 8000000 & 8000000 & 6400000 & 6400000 & 6400000 \\
\hline Estimated price per attendance & 80 & 67 & 61 & 150 & 53 & 52 \\
\hline $\begin{array}{l}\text { Estimated price per attendance } \\
\text { based on planned capacity }\end{array}$ & 34 & 34 & 34 & 33 & 33 & 33 \\
\hline Estimated total cost to provider per year & 610902 & 596753 & 606528 & 523720 & 518373 & 520623 \\
\hline Estimated cost per attendance & 30 & 25 & 23 & 62 & 21 & 32 \\
\hline $\begin{array}{l}\text { Estimated cost per attendance } \\
\text { based on planned capacity }\end{array}$ & 13 & 13 & 13 & 14 & 13 & 13 \\
\hline
\end{tabular}


180 and 150 attendances daily (in and out of London respectively), then the price to the NHS per attendance would be £34 for London-based service and $£ 33$ for non-London-based service. If the price per attendance is calculated using patient numbers provided by the centres, then this ranges from $£ 52$ to $£ 150$ per attendance for different sites (Table 6).

The estimated cost of the NHS providing a centre for the 5-year period was $£ 3023635$ for Londonbased services and £2 604525 for out of London services. If the centres operated at their planned capacity, the cost per attendance would be $£ 13$. Based on actual daily attendance, cost per attendance varied by centre from $£ 21$ to $£ 62$.

\section{The wider health economy}

Some local commissioners felt that the commuter walk-in centres brought benefits to commuters, local people, and the PCT. The benefit for commuters and workers was increased convenience for a group that had difficulty getting an appointment with their own GP. The benefit for local people was an alternative service that improved access to local primary care services. Four of the PCT managers hoped that the new service would reduce demand for other services in their locality, particularly emergency departments. However, there were concerns that the service was focused on the 'worried well' or was simply not a priority given the health needs of the local population:

\section{'It will hopefully divert from A\&E where it is appropriate.'}

Some PCT managers had immediate concerns about dealing with the cost of the service after handover from the Department of Health, but the underlying plan was to reassess the need for such a service in the context of their local urgent care strategy. They discussed the future of the centres in terms of expanding the services provided, sometimes in a way that is consistent with general rather than commuter walk-in centres, for example, extension of opening hours and the types of services on offer:

'I certainly think that if we're a national health service, we actually have to have a care for the health of the whole nation. An area like [name of area], has got some of the greatest deprivation and poor health outcomes in the UK. So actually ... a [commuter walk-in centre] is never going to be the top of our list of priorities.'

'It's easy to see circumstances where the walkin centre may not be part of the long-term strategy.'

\section{DISCUSSION}

\section{Summary of main findings}

Pilot walk-in centres placed near train stations for commuters had low activity levels and high costs. Based on the limited data of this study, the centres were under-utilised at the time of evaluation, and this is partly related to poor locality; one centre has a particularly poor location. Although attendance rates may improve in the future, this may be a costly way of providing care to commuters and may not be sustainable in the future in the context of primary care trust commissioning. A policy of placing walk-in centres in areas of high worker density to provide care for workers may work more successfully.

\section{Strengths and limitations of the study}

The strength of this evaluation was the use of multiple methods to address a range of research questions about this pilot service. A key limitation was the lack of access to activity data and detailed costing data for the centres; the study used activity data reported by centre managers and activity data reported by centre staff on the days when the user questionnaire was handed out. The user survey is likely to have suffered from sampling bias as well as non-response bias. Differences in sampling bias and non-response bias between centres may account for differences between the six centres. The simple economic costing is based on limited activity and costing data. The difference between price and cost is profit to the service provider; however, both the price and cost estimates have a large amount of uncertainty around them. The pedestrian data are sensitive to the times of day that data collection occurred.

\section{Comparison with existing literature}

Attendees at the commuter walk-in centres are different from those of general walk-in centres in ways aligned with the policy of providing health care to commuters. In the national evaluation of walk-in centres, only $10 \%$ of users reported being in the area for work/commuting, compared with $62 \%$ in the present study describing themselves as commuters. ${ }^{2}$ Similarly, only $6 \%$ of users lived further than 10 miles away from a general walk-in centre compared with $22 \%$ of users of commuter walk-in centres. ${ }^{2}$ In a study of four general walk-in centres, between $78 \%$ and $91 \%$ of attendees lived within $6 \mathrm{~km}$ of the site, ${ }^{10}$ with patients attending the two London walk-in centres living closer than those attending the walk-in centres outside London. ${ }^{11}$ The location of centres near to train stations did not appear to be important because people did not use them on their way to work. Rather, location near to people's work was important. Previous research has identified the 
importance of location of walk-in centres to their success. ${ }^{4}$ The estimated cost per attendance based on price paid for the centres, with the assumption that they work at planned capacity, was $£ 33$. This is higher than the £8 per attendance at a general practice nurse, but comparable to the $£ 30$ per attendance at a general practice, £35 per attendance at a non-24-hour emergency department, and £27 for a walk-in centre attendance. ${ }^{7}$ However, none of the commuter walk-in centres were working at planned capacity.

\section{Implications for future research and clinical practice}

Commuter walk-in centres could be provided by the NHS using the standard walk-in centre model rather than through independent provision. The advantage of independent provision is that it is in line with current policy and is a quick way of increasing capacity in order to offer NHS services in a new way. One disadvantage is that the NHS is committed to a contract that can lead to a very high price per patient if the service is under-utilised. Furthermore, evaluation of publicly-funded services is essential yet is being hampered when services are provided by independent companies, due to commercial sensitivity around activity data and costs. ${ }^{12}$

It seems sensible to ask whether commuter walkin centres are the most cost-effective way of increasing access to care for minor illness in a working population. Alternative modes of delivery include extending general practice opening hours, walk-in facilities attached to general practices in areas of high worker density, nurse-led walk-in centres, workplace-based doctors or nurses, and promotion or expansion of the role of pharmacists. The costs and benefits of these alternative strategies should be compared. There are also lessons here for new GP-led services: location is a key characteristic of a healthcare facility if it is to generate attendance from the target population.

\section{Funding body}

This work was undertaken by the Medical Care Research Unit which is supported by the Department of Health $(017 / 045)$. The views expressed here are those of the authors and not necessarily those of the Department of Health

\section{Ethical approval}

Ethics approval was given by Brighton East LREC (07/Q1907/22)

\section{Competing interests}

The authors have stated that there are none.

\section{Discuss this article}

Contribute and read comments about this article on the Discussion Forum: http://www.rcgp.org.uk/bjgp-discuss

\section{REFERENCES}

1. NHS Executive. NHS primary care walk-in centres. HSC 1999/116. Leeds: NHS Executive, 1999.

2. Salisbury C, Chalder M, Manku-Scott T, et al. The national evaluation of NHS walk-in centres. Final Report. Bristol: University of Bristol, 2002. http://www.phc.bris.ac.uk/phcdb/pubpdf/pubs/257.pdf (accessed 28 Jul 2009).

3. Salisbury C, Hollinghurst S, Montgomery A, et al. The impact of colocated NHS walk-in centres on emergency departments. Emerg Med J 2007; 24(4): 265-269.

4. Chalder M, Montgomery A, Hollinghurst S, et al. Comparing care in walk-in centres and at accident and emergency departments: an exploration of patient choice, preference and satisfaction. Emerg Med J 2007; 24(4): 260-264.

5. Department of Health. New surgeries offer commuters fast-track to treatment [press release]. London: Department of Health, 2004. http://www.dh.gov.uk/en/Publicationsandstatistics/Pressreleases/DH_ 4093426 (accessed 28 Jul 2009).

6. Coster J, O'Cathain A, Nicholl J, Salisbury C. User satisfaction with commuter walk-in centres. Br J Gen Pract 2009; 59(569): 10.3399/bjgp09X473169.

7. Curtis L. Unit costs of health and social care 2007. Canterbury: Personal and Social Services Research Unit, 2007.

8. NHS Employers. Pay Circular (AforC) 4/2007: pay and conditions for NHS staff covered by the Agenda for Change agreement. http://www.nhsemployers.org/Aboutus/Publications/PayCirculars/Do cuments/Pay_Circular_AfC_4-2007_aw.pdf (accessed 28 Jul 2009).

9. Ritchie J, Spencer L. Qualitative data analysis for applied policy research. In: Bryman A, Burgess RG (eds). Analysing qualitative data. London: Routledge, 1994, pp: 173-194.

10. Maheswaran R, Pearson T, Munro J, et al. Impact of NHS walk-in centres on primary care access times: ecological study. BMJ 2007; 334(7598): 838-841.

11. Maheswaran R, Pearson T, Jiwa M. Repeat attenders at National Health Service walk-in centres - a descriptive study using routine data. Public Health 2009 Jul;123(7):506-10. Epub 2009 Jul 14.

12. Delamothe T. The problem with ISTCs (Editorial). BMJ 2009; 338: b1863. 